\title{
LA SOLIDARIDAD DE LOS WAMANIS Y LAS LAGUNAS CON LOS POBRES: \\ El origen del venado en los mitos Quechuas
}

\author{
Néstor Godofredo TAIPE CAMPOS \\ Asociación de Estudios Socioculturales Andino Amazónicos (Perú) \\ ngtaipe@yahoo.com
}

\begin{abstract}
THE SOLIDARITY OF THE WAMANIS AND THE LAGUNAS WITH THE POOR: The origin of the deer in the quechuas myths
\end{abstract}

Resumen: Este artículo estudia seis relatos míticos quechuas del nororiente de la provincia de Tayacaja en Huancavelica (en los Andes Centrales de Perú) sobre la solidaridad del Wamani (dios montaña) y las lagunas con los hombres pobres; el castigo a los ricos; y, el origen del venado. La estructura narrativa está organizada alrededor de la solidaridad intrageneracional, cuya transgresión acarrea castigos míticos de regresión metafórica del orden cultural al orden natural: de humano a venado.

Abstract: This article studies six mythical Quechua narratives from the north-east of the Tayacaja province in Huancavelica (in the Central Andes of Peru) on the solidarity of the Wamani (mountain god) and lagoons with poor men; the punishment of the rich; and, the origin of the deer. The narrative structure is organized around intragenerational solidarity, whose transgression carries mythic punishments of metaphorical regression from the cultural order to the natural order: from human to deer.

Palabras clave: Mitos Quechuas. Dios Montaña. Lagunas. Valores Sociales. Metáforas. Cultura. Naturaleza Quechua Myths. Mountain Gods. Lagoons. Social Values. Metaphors. Culture. Nature 


\section{Introducción}

Este trabajo desarrolla el análisis de seis relatos míticos quechuas de Tayacaja (Huancavelica, Perú) sobre la solidaridad del Wamani (dios montaña) y las lagunas con los pobres, el castigo a los ricos y el origen del venado. La estructura narrativa está organizada alrededor de la solidaridad intrageneracional, cuya transgresión acarrea, en el imaginario de los consumidores del relato, los castigos míticos de regresión metafórica del orden cultural al orden natural, mediadas por el despliegue de un conjunto de valores y anti-valores sociales.

Organizo la exposición en tres partes. La primera presenta al mito de referencia; la segunda, aborda al premio de las deidades al pobre honesto; y, la tercera trata de la transformación del codicioso en venado. En el anexo va el corpus completo de los relatos.

El mito de referencia

Relato $\mathbf{N}^{\circ}$ 1: Solidaridad del Wamani con los pobres y el origen del venado: Relato de Eugenio Claros, registrado en Pongollo (Salcahuasi, Tayacaja) en 1987.

Un día un hombre se comprometió con la mayordomía de una fiesta. Él no tenía nada. Durmiendo en su casa con su mujercita dijo: “ ¿Cómo vamos a estar así? Iré a trabajar y tú tejerás mantas aquí”.

Después, por la madrugada, su mujer le alistó comida. Y acompañado de su hija, se fue por un lejano camino. Cuando iban caminando se anochecieron debajo de un cerro. Arreglaron con sus mantas y durmieron.

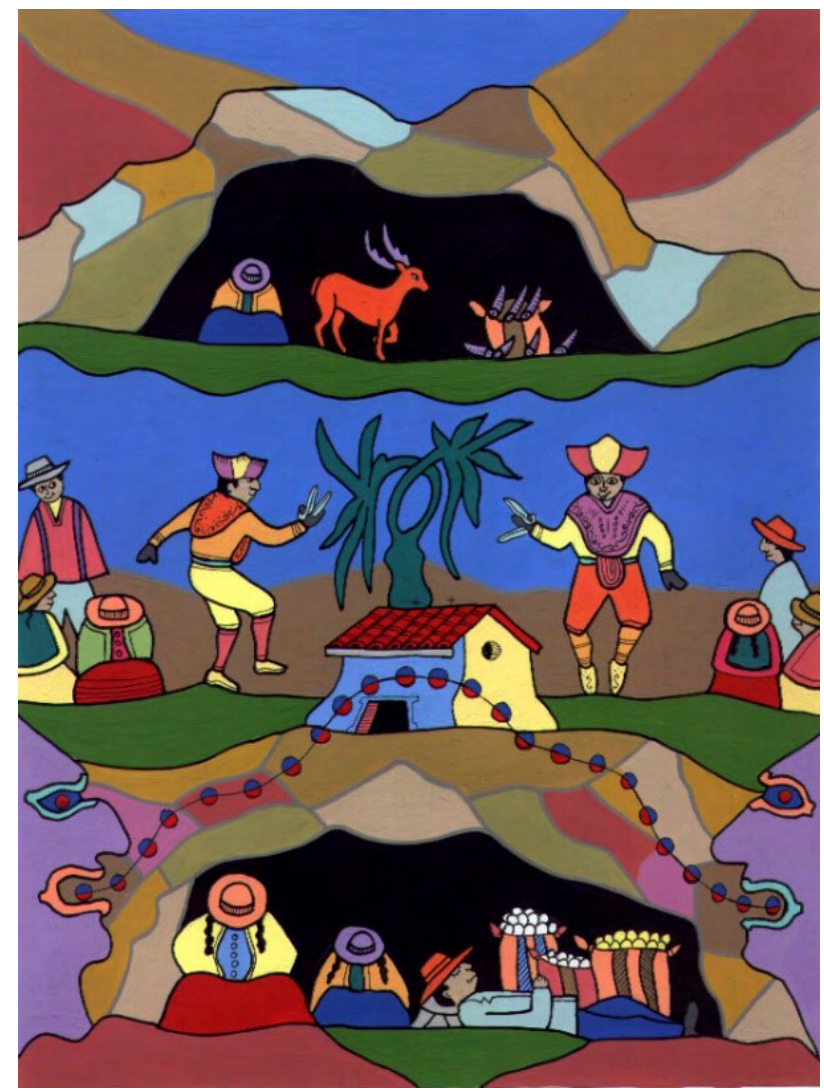

Ilustración 1: De codicioso a venado (Josué Sánchez Cerrón). 
El padre se despertó casi a la media noche. En eso dice que el cerro de un lado le llamaba al cerro del frente. El hombre dice que escuchaba. Los cerros conversaban: “QQué le darás tú?”, preguntó uno. El otro respondió: "Yo le daré oro".

Como el hombrecillo estaba muy preocupado, el cansancio lo durmió. Cuando despertó, encontró a su lado dos costales llenos de oro. El hombre ya ni fue a buscar trabajo.

Dice que hizo una buena fiesta; hasta hizo una casa nueva. Por eso, su hermano que era un envidioso, también entró a la mayordomía. Igual se fue con su hija y durmió en el mismo lugar. Cuando despertó, los cerros se llamaban. El hombre se puso alegre: Creía que a él también le darían oro. Cuando despertó, al amanecer, tenía cuernos, y de vergüenza ya no regresó. Luego se convirtió en venado. Ahora ya no se deja ver por la gente.

Este mito podría ser una variante del origen del venado que aparece cuando Huatyacuri, en Dioses y hombres de Huarochirí, en una confrontación con su concuñado, da un enorme grito y éste se espanta, se transforman en venado y huye; su mujer dijo: "Voy a morir con mi esposo querido' y, así diciendo, siguió al venado". La confrontación surge precisamente porque el héroe es "pobre" y el concuñado es un gran "señor", que por petición de éste compiten en varias pruebas con la finalidad de "humillar" a Huatyacuri.

Al convertirse en venados, aumentaron, después tuvieron una reunión para determinar cómo debían comer a los hombres (aquellos tiempos, los venados comían a la gente), pero “una cría se equivocó y dijo: ‘Cómo nos han de comer los hombres?’, al oír estas palabras, los venados sintieron temor y se dispersaron. Desde entonces se convirtieron en comida humana" (de Ávila, 2013 [¿1598?]).

\section{Las deidades premian al pobre honesto}

El discurso del grupo mítico analizado despliega a dos tipos de hombres, uno rico y otro pobre. Obviamente cada relato mítico presenta sus propias particularidades que las hace diferir en forma, mientras que la estructura es siempre igual. En cuatro de los seis relatos, el rico y el pobre son hermanos, mientras que los dos restantes aluden a hombres ricos y pobres sin relaciones de parentesco (ver el corpus de los relatos en el anexo).

En cuatro relatos el pobre se compromete a realizar la fiesta del pueblo. En otros dos no aparece el motivo anterior. El pobre y su mujer acuerdan que ella se quedará a tejer mantas, mientras que él, acompañada de su hija, irá a trabajar, razón por la cual emprendieron un lejano camino.

El motivo de la ausencia del pobre está relacionado con la abnegación porque a pesar de su pobreza intenta cumplir con el compromiso de realizar la fiesta de su comunidad, pero también se relaciona con el altruismo, en forma de solidaridad de parte del hermano pobre en favor del hermano rico, ayudando a buscar al ganado de éste. No obstante, existe una actitud invertida, de insolidaridad, de parte del rico con relación al pobre.

Ser responsable de la ejecución de una fiesta de un pueblo (mayordomo) es un compromiso que adquiere el individuo frente a la colectividad. En algunas comunidades andinas, como las estudiadas en esta investigación, las mayordomías son rotativas y todos los comuneros deben cumplir con esa obligación, ello les permite legitimar el acceso al uso de los recursos comunales (tierras, pastos, bosques, aguas, etc.), y a ocupar cargos de administración en la comunidad. Sin embargo, las condiciones económicas de los comuneros no son iguales, siempre hay ricos y pobres. Cuando los ricos realizan las fiestas, en algunas comunidades, existe una suerte de redistribución de la riqueza entre la comunidad; en otras las fiestas sirven para acrecentar los bienes de los ricos. Cuando los pobres se comprometen 
a realizar la fiesta, al no poder cubrir los gastos que demanda, se ven obligados a abandonar la comunidad temporalmente y buscar trabajo durante varios meses del año, a fin de ahorrar dinero y afrontar el compromiso adquirido ante su pueblo.

La ausencia, aunque con diferentes formas, se repite en todos los relatos. Unas veces el pobre viaja en busca de los danzantes y músicos para hacer su fiesta, cuando va a buscar trabajo, cuando va a buscar las vacas de su hermano rico, cuando va al cerro a cortar paja para techar su casa y hacer la fiesta.

Todos los hombres que se ausentan, por uno u otro motivo, son sorprendidos por la noche en los cerros o cerca de las lagunas. Unos duermen en una cueva, otros en la intemperie o en unas chozas viejas. Desde el punto de vista de la oposición veracidad/engaño y considerando que los donantes de los premios/castigos son los Wamanis (dioses montaña) o las lagunas ${ }^{1}$, el hecho de pasar la noche en estos espacios sagrados, es una manera en que los hombres exponen sin proponérselo su pobreza ante las deidades. A esta forma de exposición la llamaré verdad pasiva (opuesto al engaño activo y premeditado). Se supone pues, que los pobres exponen un conjunto de signos que permiten reconocer su condición social y económica: sus vestidos, otras prendas, sus propios cuerpos, las formas cómo viajan, etc.

Con excepción del hombre pobre de un relato (que duerme en el interior de una cueva), todos los demás, como a la media noche despiertan y oyen que los cerros o las lagunas conversan, y al referirse a ellos los tratan como "sus visitas", y se ponen de acuerdo en el regalo que les otorgarán, y casi siempre es oro y plata.

Al día siguiente, el pobre, al despertar, encuentra a su lado dos costales llenos de oro, con lo que hace una fiesta buena y construye una casa nueva. Otro consigue que a cuenta de trabajo le den músicos y danzantes. Otro hombre halla a su lado dos costales de plata y uno de oro con los que realiza la fiesta. En otros mitos los hombres hallan entre sus bultos dos piedras: una de oro y otra de plata, con los que compran unas terneras y empiezan a tener sus propias ganaderías que van siempre en aumento. El último encontró a su lado oro y plata, tesoros con los que compró ropa para sus hijos, hizo una casa y realizó la fiesta mejor que su hermano acaudalado. Temporalmente, para estos hombres se cierra un ciclo de pobreza e inician otro de riqueza.

La inversión de pobre en rico se realiza mediante la donación mítica del dios montaña o de la laguna. En los relatos analizados por Ansión (1982 y 1987), el premio se realiza por el cumplimiento de los rituales que efectúa el hombre. En cambio, en mi análisis, por lo menos de manera explícita, no surge ritual previo alguno. Sin embargo, ningún hombre que pasa la noche en el campo (en el cerro, una cueva, un bosque, una puna o cerca de una laguna) lo hace así nomás. Siempre mastican hojas de coca y fuman cigarrillos para evitar algún "daño". Muchas veces los hombres portan algún objeto metálico como una daga, con el cual hincan al lugar donde descansarán para evitar que la tierra, el cerro o la laguna los devore. Otras veces entierran levemente unas semillas y restos de coca, también llevan aguardiente y derraman unas gotas en la tierra como ofrenda a las deidades.

\section{De codicioso a venado}

El cambio de condición de pobre en rico, despierta la envidia de los hermanos o ajenos ricos. La envidia, como el deseo de posesión de los bienes ajenos, viene asociada con el

\footnotetext{
1 J. J. García Miranda describe que "Wamani es un espíritu que mora las montañas más elevadas y protege la naturaleza y los pueblos de su entorno" (2006: 79). El uso de la nominación de Wamani es propio del área chanka (Huancavelica, Ayacucho, Apurímac) y wanka (Junín), lugares donde también le llaman Tayta Urqu y Apu (no obstante, Apu es más utilizado en la zona quechua del sur comprendida por los departamentos de Cusco, Arequipa y Puno). En otros lugares el dios montaña adopta los nombres de Jirka, Achachi, Apu, Awki, Achachila, Apu-urqu, Apusuyu, Apu Roal, Awkillu, Awkikuna, Urqu Taytacha, Señor, Tayta, Viejo, Yaya (García, 1998).
} 
egoísmo; es decir, que todo lo quiere para él. En un relato el hombre rico calumnia de ladrón al pobre y hace que éste, en defensa, narre el origen de su riqueza.

Los ricos envidiosos y egoístas, una vez obtenida la información del origen de la riqueza del pobre, repiten la misma hazaña de éste. Un hermano envidioso tomó la mayordomía y hace lo mismo que el otro; es decir, existe la pretensión de un engaño activo y premeditado (opuesto a la verdad pasiva). Quiere hacer creer a los dioses montaña que él también es pobre, pero los dioses castigan a este hombre, que cuando despierta estaba con cuernos y de vergüenza ya no regresó, se convirtió en venado y ya no se deja ver por la gente. Temporalmente, para estos hombres se cierra un ciclo de pertenencia al orden de la cultura, y mediados por la envidia, retornan metafóricamente al orden de la naturaleza (a la no-cultura) iniciando otro ciclo temporal cualitativamente diferente al primero.

Otro rico se disfraza de pobre, con zapatos muy viejos y ropas harapientas, se dirige al mismo lugar e hizo igual que el pobre, tratando de engañar a los dioses. Al siguiente día encontró a su lado un costal de cuernos y dos de huesos y regresó amargado.

Los hermanos ricos en dos relatos, envidiosos y egoístas, fueron también a dormir al borde de las lagunas, y como a la media noche escucharon que las lagunas Yanaqucha y Misaqucha (ver ilustración 2) se ponían de acuerdo para darles un regalo. Al siguiente día encontraron en sus mantas muchos cuernos que las llevan a sus casas pensando que sería para que aumente sus animales, pero éstos empezaron a morirse, mientras que el ganado de los hermanos pobres iba en aumento. Los ricos les hacen "brujería" a sus hermanos, como no les "llegó" el hechizo, mueren ellos mismos.

El hermano rico del último relato, vistiendo ropas viejas, hizo lo mismo que su hermano pobre. Por la noche escuchó que dos mujeres (las lagunas) se llamaban: “QQué le vamos a regalar a nuestra visita?". "Tú rabos y yo cuernos", había respondido. Al día siguiente despertó y tenía cuernos y rabo y se transformó en venado.

El premio o el castigo surgen a partir del tipo de relación de solidaridad/insolidaridad entre integrantes de la misma generación (especialmente entre hermanos). Las condiciones de la ruptura (la envidia, el egoísmo, la calumnia y el engaño) son cualidades de los ricos, y son los detonadores del surgimiento del castigo mítico que consiste en el retorno metafórico

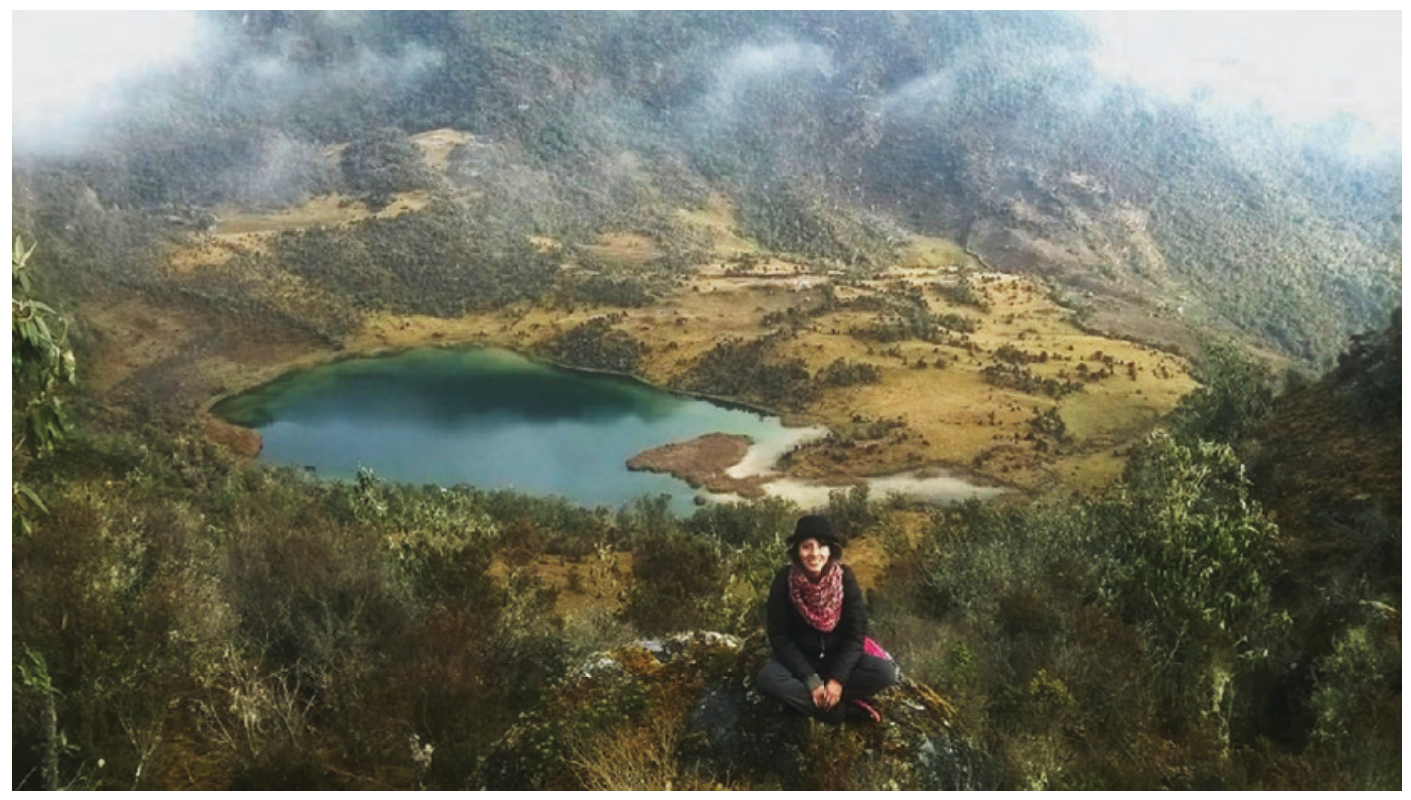

Ilustración 2: Laguna Misaqucha en Salcabamba (Martha Lazo, 2017). 
del orden cultural al orden natural. Los ricos que pretenden engañar a los dioses montaña o a las lagunas se convierten en venados.

En "Lapia Huauki (Imanuipash tarush yurimusha)" ["El hermano codicioso (El origen del venado)"], relato integrante de las Fábvlas qvechvas de Adolfo Vienrich (1961), se encuentra la transformación mítica del hombre codicioso en venado, relato reproducido también por Isabel Córdova (1979) y Benjamín Gutiérrez (s/f). Reynaldo Martínez (s/f) también presenta una versión parecida. La particularidad de este relato es que los elementos que intervienen en el premio son la pampa, la cueva y la puna; la primera le da maíz blanco que se convierte en plata, la segunda maíz morado que se convierte en cobre y la tercera maíz amarillo que convierte en oro. Cuando el rico intenta engañarlas, la piedra le hizo crecer cuernos en la frente, la pampa rabos y la puna cola. Este hombre se convirtió en venado.

Por su parte, César Toro Montalvo (2016) presenta otro relato con la misma estructura: el que ayuda al pobre es un anciano que dice ser dueño de todos los animales, le pide al pobre (que busca cazar para alimentar a su familia) que no mate a sus animales del monte y le da maíz que se convierte en oro y plata y los cereales que arroja al corral se convierten en ganado. El hermano rico del relato, por pretender engañar al anciano, recibe un chullu (una gorra) y al llegar a su pueblo le aparece cuernos y patas y se convierte en venado.

Luis Gonzalo (2011) narra que un hermano mayor, haciéndose pasar por mendigo, trata de engañar a los volcanes Solimana (Arequipa) y Sara-Sara (Ayacucho), el primero le regala un sombrero y el segundo unas botas. Los volcanes Ferurare ( $i$ ?) y Coropuna (Arequipa) le regalan azucenas y abrigo. Cuando regresó a su pueblo, lo perros los persiguieron y asustaron, escapó y no regresó más. Se había convertido en venado. El sombrero y la azucena eran los cuernos, el abrigo la piel y las botas las pesuñas.

Carmen Escalante y Ricardo Valderrama (1997) narran de un hombre que quitaba tierras a su hermano. Él tenía una flor de clavel en la cabeza. Esta flor se convirtió en cuernos; por tanto, se convirtió en venado y corriendo se refugió en los cerros. Entonces comer venado es un tabú, es como comer a otro humano. La violación de este tabú puede llevar al transgresor hacia la condenación.

La naturaleza, desde el punto de vista anterior, debe ser entendida como la no-cultura (Lotman y Uspenskij, 1979; Lotman, 1998). La riqueza significa acumulación de bienes. En comunidades como las estudiadas el rico es tal a costa de la privación de los pobres. En consecuencia, existe una suerte de control social que orienta hacia la redistribución de las riquezas entre los que menos bienes tienen. Esto significa compartir, por ejemplo, los productos derivados de la ganadería (leche, queso, suero como menciona un mito, donde el hermano rico no comparte con el hermano pobre). En cambio, el pobre transformado en rico sí redistribuye sus bienes en favor de su comunidad a través de la realización de la fiesta.

La reciprocidad sigue siendo un elemento central en el funcionamiento de las sociedades andinas. Su quebranto a través de la unilateralidad es sancionado de alguna manera. La envidia es una forma de ruptura de la solidaridad entre los hombres porque se desea el bien ajeno. El egoísmo es también otra forma de la misma ruptura, porque se quiere bienes sólo para ego y no para alter. Pero, todo lo que se quiere o se hace sólo para ego, desde el punto de vista moral, es un antivalor social. La veracidad es una forma de reciprocidad entre los hombres quebrada por el engaño y la calumnia. El engaño es positivo cuando el hombre se enfrenta con seres maléficos como el diablo y el "condenado" (Monge, 1993), o cuando los animales protegen a los débiles como el cóndor que miente a la perseguidora para salvar al niño que oculta bajo sus alas (Arguedas e Izquierdo, 2011). Pero el engaño entre los hombres es negativo, más aún si se trata de engañar a deidades protectoras como los Wamanis o las lagunas. En consecuencia, los transgresores son ubicados fuera de la cultura, en la nocultura, de ahí su conversión metafórica de hombres en venado, de la cultura en naturaleza. En el relato de Escalante y Valderrama existe un signo aculturado, la condenación por causa del consumo de carne de venado (de "humano"), es de influencia católica. En cambio, "co- 
mer" al cuerpo y "tomar" la sangre de Cristo, es sagrado, a pesar de que hay un canibalismo simbólico.

En este caso, la metáfora del retorno del orden de la cultura al orden de la naturaleza está actuando como una operadora simbólica que regula el funcionamiento de los valores y las reglas sociales entre los hombres donde se producen, circulan y recepcionan los relatos míticos analizados. Y esta es la función normativa y modelante principal de los mitos en cuestión.

Algunos de los relatos señalan que los hermanos ricos, al no lograr sus propósitos, empujados por la envidia, acrecientan su maldad deseando e intentando la muerte de su hermano a través de la brujería, que en un relato aparece con efecto inverso, porque al no ser efectivo en su hermano, se vuelve hacia él y provoca su muerte. Entonces estamos ante un caso en el que la ruptura de la solidaridad intrageneracional lleva también hacia la muerte del transgresor.

Queda claro que los Wamanis y las lagunas están ligados al ganado y que poseen riquezas en forma de minerales (Ansión, 1987); asimismo, los dioses montaña y las lagunas no actúan solos, sino de modo concertado, por eso se ponen de acuerdo para premiar a los pobres o castigar a los ricos.

Finalmente, como señalara Juan Ansión: "Los productos de la tierra, el ganado y la riqueza mineral son los tres tipos de riqueza que puede ambicionar un campesino. Pero la riqueza que le es posible acumular y tener como reserva es sobre todo el ganado. El campesino venderá un animal el día que tenga que hacer frente a un gasto extraordinario, y si tiene algo extra para invertir, es con frecuencia ganado lo que comprará" (1987: 121). El ganado y los minerales (oro y plata) son los tipos de riqueza que, los relatos míticos estudiados, despliegan de modo conjunto o disjunto de los sujetos.

\section{Conclusiones}

El análisis de los mitos referidos muestra el papel de la regresión metafórica del orden cultural al natural que regula el funcionamiento ideal de los valores y las reglas sociales entre los hombres que consumen estos relatos. Y esta es la función normativa y modelante principal de los mitos en cuestión.

En el proceso de transformación metafórica de los transgresores en venados, se identifican la solidaridad e insolidaridad como valor y desvalor dominantes y que se encuentran interconectados sistémicamente con otros valores y desvalores jerárquicamente inferiores que son la abnegación y la envidia, el altruismo y el egoísmo, la veracidad y el engaño, y la no-calumnia y la calumnia.

Finalmente, el mito contemporáneo del origen del venado parece derivar de un mito antiguo registrado por Francisco de Ávila en Dioses y hombres de Huarochirí. Obvio que presenta variaciones de forma, aunque la estructura es la misma. Los cambios de forma son explicados porque los mitos, al viajar en el tiempo y el espacio, toman los nuevos elementos de su contexto en cada narración realizada.

\section{ANEXO: Corpus de los relatos analizados}

Relato $\mathbf{N}^{\circ}$ 2: Wamanis, el diablo, la santa patrona y el pobre: Relato de Lucía Reyes, registrado en La Loma (Salcahuasi, Tayacaja) en 1987.

En una fiesta del mes de enero, fiesta donde hay danzantes [de tijeras], los más adinerados hicieron emborrachar a un hombre pobre. Este había dicho: 'Yo también puedo hacer la fiesta'. Y así se comprometió hacer la fiesta del año próximo. Así pues, la fiesta debió realizarla el 1 de enero. Y el hombre se fue a contratar un arpista, un violinista y a los danzantes, a fin de pagar con su trabajo. Cuando el hombre iba a traerlos, se había anochecido en la cordillera y durmió en una cueva. A la media noche, los cerros se llamaban y el pobre 
hombre ni cuenta se daba. ‘¿Qué busca ese hombre?’, preguntó uno de los Wamanis. El otro respondió: 'Dice que es mayordomo y es pobre, no tiene dinero y va a encontrarse con un hacendado en ese calvario. Vamos ayudarle', había dicho.

Cuando arribó al calvario, llegó un hombre cabalgando un caballo blanco. Y el pobre le dice: 'Quiero trabajar, y a cuenta necesito un adelanto'. El hombre del caballo respondió: 'Yo te traigo a los músicos por seis días de trabajo'. Así pues, hicieron el trato. Los comuneros no creían que este hombre realizaría la fiesta. Los músicos y los danzantes de los otros mayordomos ya estaban allí, en la plaza. El pobre estaba desesperado, estaba con su chicha fermentada y con sus licores. En eso escuchó que detrás de su casa afinaban un arpa y un violín. Cuando tocaron, hasta sus danzantes bailaron en el aire. Cuando les daban chicha y aguardiente, los danzantes se negaban a recibir diciendo: 'Nosotros venimos con nuestra propia bebida'. Al llegar a la plaza les demostraron su superioridad a los músicos y danzantes de los otros mayordomos. La comunidad quedó admirada por la calidad de los músicos y los danzantes.

Cuando terminó la fiesta, el hombre tenía que ir a trabajar por seis días. El patrón [el demonio] llegó y se lo llevó en la grupa de su caballo. Así le hizo llegar hasta la hacienda [el infierno].

El primer día le hizo pastar cuyes, pero ese día era un año. Con un tronador pastaba y a su vez tenía que golpear una ojota de acero hasta que se haga hueco la planta. El Wamani le aconsejaba que debía de correr a una piedra, sino los cuyes se los comerían.

El segundo día le hace pastar gallos, con las mismas dificultades que con los cuyes.

El tercer día pace cabras, sucede igual.

El cuarto día lo mandan a juntar leña.

El quinto día va traer esa leña.

El sexto día dice: 'Ahora voy a cumplir con mi trabajo'. Le dan una candelilla para que prenda la leña. No podía. Hasta que la Santa Patrona de su pueblo le dijo: 'Moviendo esa candelilla arrójalo a la leña'. Y cuando hizo eso, recién se prendió. Las leñas estaban en un cilindro y al ser prendidas, de allí salieron los espíritus y el alma de un cura. Del cilindro volaron varias palomitas.

Después le dice al patrón: 'Ya cumplí con el trabajo'. El patrón le hizo cruzar un río. Después la Santa Patrona de su pueblo le dijo: 'Cuando llegues al calvario vas a ver dos palomitas y va caer sus heces. Tú vas a tender tu manta para recogerla: Una de ellas te va dar color blanco y, la otra, color amarillo, a las que debes cargar sin abrir y las vas a guardar en unos cajones de tu casa'. Así llegó a su casa después de seis años. Su esposa había pensado que se había muerto y hasta sus hijos le habían desconocido. Al día siguiente, cuando vio los cajones donde había guardado las heces, estaban llenos de oro y plata. El pobre se volvió rico.

Relato $\mathbf{N}^{\circ}$ 3: Wamanis que se solidarizan con los pobres: Relato de Amada Campos, registrado en Miraflores (Salcabamba, Tayacaja) en 1987.

En aquellos tiempos existía un rico y un pobre que se encontraron en una fiesta de pascua, en la que el pobre tomó la mayordomía. El rico decía: “¿Con qué dinero hará la fiesta este pedazo de qutu [bocio]?". El pobre se vio obligado a viajar, llevando un poco de fiambre que su esposa le había preparado. Se anocheció cuando iba por un monte. Masticó su coca y se durmió. Cuando despertó, escuchó que los cerros se llamaban: "¿Qué le vamos a regalar?", diciendo. El otro respondió: "Yo le voy a dar un costal de oro". "Y yo dos costales de plata". Cuando al día siguiente se despertó, el hombre halló a su lado dos costales de plata y uno de oro; y los acarreó a su casa. El rico le había preguntado: “¿De dónde traes tanta plata? Debes ser ratero cuando traes mucha plata. Te voy a matar", le había dicho. Entonces le narró que el Tayta Wamani le había regalado porque él era pobre. El rico también fue al mismo lugar, con sus zapatos muy viejos y ropas harapientas. Cuando se despertó a la media 
noche, los cerros se llamaban: “QQué le vamos a regalar a nuestro amigo?”. El otro Wamani respondió: "Yo le voy a dar un costal de cuernos de vaca". El otro dijo: "Yo voy a darle dos sacos de huesos". Al amanecer el rico sólo encontró un costal de cuernos y dos de huesos y regresó amargado.

Relato $\mathbf{N}^{\circ}$ 4: Lagunas que se solidarizan con los pobres: Relato de Albino Lazo, registrado en San Juan de Yananaco (Salcabamba, Tayacaja) en 1987.

Había una vez un hombre muy pobre. Su hermano, en cambio, era propietario de mucho ganado que comían en el sector de la laguna de Yanaqucha. El hermano rico le había mandado al pobre para que vea a sus vacas. El hermano pobre había hallado solo a una parte del ganado. Al hacerse de noche en la puna, se quedó a dormir en una choza, tendiendo paja durmió en ella. A altas horas de la noche, las lagunas se llamaban. Yanaqucha decía a Misaqucha: "Hermana, tenemos visita, ¿qué le vamos a regalar?". "Tú le darás plata y yo oro", había respondido. Pensativo el hombrecillo se había vuelto a dormir. Cuando amaneció, levantó su manta para que retorne, y en ella había un bulto muy pesado. Cuando vio, encontró dos piedras: Una de oro y otra de plata, a las que cargó muy alegre. Cuando llegó a su pueblo y avisó a sus vecinos sobre el suceso. Uno de los hombres, que tenía muchas vacas, le dijo: "Te cambio por una vaquilla". "Bueno", respondió el otro e hicieron el trueque. A la otra piedra también lo cambió con otra vaquilla de otro vecino. Estas vaquillas empezaron a aumentar, daban crías hembrillas y aumentaban sus animales.

Embriagándose hablaba el hombrecillo que gracias al regalo de Yanaqucha y Misaqucha tenía sus animales. Entonces, el otro hermano envidioso, había escuchado y él también se fue a dormir al borde de las lagunas. Por la noche dice que las lagunas conversaban: "¿Qué le vamos a regalar a nuestra visita?”. "Tú cuernos y yo yermo". “¿Qué será eso?”, pensando se había dormido otra vez. Al día siguiente cuando vio su manta sólo halló cuernos en su manta. "Debe ser para que aumente mis animales", pensando se los llevó. En su casa lo había guardado. Sus animales eran muchos, pero a pesar de ello, a su hermano ni siquiera queso, ni leche le daba, hasta que se acabaron. Por eso dice que hasta brujería le hizo a su hermano; y, contrariamente, los animales de éste iban en aumento. Así, sin nada, encontró la muerte.

Relato $\mathbf{N}^{\circ}$ 5: Lagunas que se solidarizan con los pobres. Relato de Alejandro Lazo, registrado en Cedropampa (Salcabamba, Tayacaja) en 1987.

Hace mucho, dice, que había un hombre que tenía abundantes vacas, que comían por los alrededores de la laguna Yanaqucha. A su hermano menor le había mandado por las vacas, y cuando fue le había sorprendido la noche, quedándose a dormir en una choza vieja. Cuando por la noche se despertó dos personas se estaban llamando: "¿Qué cosa le vamos dar a nuestra visita?". Misaqucha había respondido "Yo oro y tú plata". Cuando amaneció vio su equipaje y había dos piedras muy pesadas. Retornó a su pueblo, a Cedropampa, lugar donde vivía. Así llegó donde su hermano, después avisó a sus vecinos. Uno de sus vecinos le buscó y le propuso cambiar una de esas piedras con una vaca. Así empezó a tener su vaca. Su hermano enterándose había ido a ese lugar y había dormido en esa misma choza. Y cuando despertó escuchó que hablaban: “QQué le vamos a regalar a nuestra visita?”. Contestó: "Yo waqra y tú cacho". Cuando amaneció, vio que en su equipaje había cuernos y regresó con ellos a su casa, creyendo que llevaba una fortuna. Después empezaron a morirse sus animales. A los cuernos los vela, y peor dice que sus ganados se acabaron. En cambio, de su hermano aumentó. Por eso, dice, que le mandó hacer brujería, y como no le llegó a su hermano, él mismo murió.

Relato $\mathbf{N}^{\circ}$ 6: Lagunas que se solidarizan con los pobres y el origen de los venados: Relato de Albino Lazo, registrado en San Juan de Yananaco (Salcabamba, Tayacaja) en 1987. 
Dos hermanos habían agarrado la fiesta. Uno era pobre y el otro era rico. El pobre había ido al cerro Torre a cortar paja. "Como sea haré la fiesta", iba pensando. Iba por paja para techar su casa, y en el cerro se anocheció y tendiendo paja durmió en la cordillera. A la media noche, cuando despertó, dos mujeres se llamaban. El hombre se sentó y pensaba: "Tal vez están queriendo engañarme, por eso se estarán llamando las lagunas". Entonces escuchó: "Hermana, ¿qué le vamos a regalar a nuestra visita?”. La otra mujer respondió: "Tú oro y yo plata". Así, dice que el hombre se quedó dormido. Cuando despertó, al día siguiente, donde dormía había oro y plata. Cargó alegre y regresó a su casa, incluso sin llevar la paja. Tenía muchos hijos. Compró ropa y mandó hacer una casa bonita. Hizo una buena fiesta, mejor que su hermano. Este le había preguntado de dónde había sacado tanto dinero. Su hermano le narró lo que había pasado cuando fue a cortar paja al cerro. Entonces, también él había ido poniéndose ropas viejas y se quedó a dormir en el cerro. Cuando despertó, a la media noche, dos mujeres se llamaban: “QQué le vamos a regalar a nuestra visita?”. "Tú rabos y yo cuernos", había respondido. Cuando despertó estaba transformado en venado con cuernos y rabos y se fue al monte.

\section{Bibliografía}

ANSIÓN, Juan. (1982). "Verdad y engaños en mitos ayacuchanos". En Allpanchis, № 20. Cusco: IPA, pp. 237-252.

ANSIÓN, Juan. (1987). Desde el rincón de los muertos: El pensamiento mítico ayacuchano. Lima: Gredes.

ARGUEDAS, José María y Francisco IZQUIERDO RÍOS. (2011). Mitos, leyendas y cuentos peruanos. Lima: Punto de Lectura.

ÁVILA, Francisco de. (¿1598?/2013). Dioses y hombres de Huarochirí. Traducción de José María Arguedas y estudio bibliográfico de Pierre Duviols. Lima: IEP.

CÓRDOVA, Isabel. (1979). Narradores de Junín. Huancayo: UNCP.

ESCALANTE, Carmen y Ricardo VALDERRAMA. (1997). La doncella sacrificada. Mitos del valle de Colca. Arequipa: UNAS/IFEA.

GARCÍA MIRANDA, Juan José. (1998). "Los santuarios de los Andes Centrales”. En Historia, religión y ritual de los pueblos ayacuchanos. Senri Ethnological Reports 9, L. Millones H. Tomoeda (eds.). Osaka: National Museum of Ethnology, pp. 51-85.

GARCÍA MIRANDA, Juan José. (2006). Cartografía de la memoria. Literatura oral del Perú. Quito: IPANC.

GONZALO, Luis. (2011). "La leyenda del venado". Disponible en http://luixrojas.blogspot. pe/2011/05/la-leyenda-del-venado.html.

GUTIÉRREZ, Benjamín. (s/f). Lecturas huancas. Huancayo: Tierra Adentro.

LOTMAN, Iuri M. (1998). La semiosfera II. Semiótica de la cultura, del texto, de la conducta y del espacio. Selección y traducción del ruso por Desiderio Navarro. Madrid: Cátedra, Universitat de València.

LOTMAN, J. M. y Boris A. USPENSKIJ. (1979). “Sobre el mecanismo semiótico de la cultura”. En Semiótica de la cultura. J. M. Lotman y Escuela Tartu (eds.). Madrid: Cátedra, pp. 67-92.

MARTÍNEZ, Reynaldo. (s/f). La fábula quechua. Estudio y recopilación de la mitología andina. Lima: San Marcos.

MONGE CÓRDOVA, Pedro S. (1993). Cuentos populares de Jauja. Huancayo: UNCP/ Munic. Prov. de Jauja.

TORO MONTALVO, César. (2016). Mitos y leyendas del Perú. Sierra. Lima: Fondo Editorial Cultura Peruana.

VIENRICH, Adolfo. (1961). Fábvlas qvechvas. 2da Edición. Lima: Ediciones Lux.

\section{3}

